\title{
The Effect of Brand on the Evaluation of Websites
}

\author{
Antonella De Angeli, Jan Hartmann, and Alistair Sutcliffe \\ Manchester Business School - University of Manchester \\ Booth Street West - Manchester, M15 6PB, UK
}

\begin{abstract}
The effect of brand on consumer attitudes towards real and virtual goods is largely documented in consumer psychology and marketing. There is an obvious link between the design of a website and its brand. Yet, this effect has attracted little attention from the HCI community. This paper presents empirical evidence showing that brand attitude influences the evaluation of websites. The effect was reliable across different measures: people holding better attitudes were more positive in the evaluation of aesthetics, pleasure and usability. A sample of students $(\mathrm{N}=145)$ with a background in HCI was tested, suggesting that brand may influence the output of expert evaluators. The study provides support to the proposition of UX as a contextual-dependent response to the interaction with computing systems and has important implications for the design and evaluation of websites which are discussed in the conclusion.
\end{abstract}

\section{Introduction}

There is a pervasive move in HCI research and practice to consider hedonic aspects of user experiences alongside pragmatic qualities in the evaluation and design of interactive systems [1-3]. Responses such as emotions, aesthetic judgments and fun are among the most prominent aspects of experience investigated [4-6]. The User Experience (UX) is a complex response to the interaction with computing systems [1]. This response is a consequence of individual predispositions of the user (e.g., attitudes, motivations and needs), characteristics of the interactive system (e.g., purpose, functionality and usability) and contextual dependencies (e.g., task and environment). Thus, UX is elicited by an array of variables which combine to determine overall quality judgments [7].

The effect of brand on consumer attitudes towards real and virtual goods is well documented in consumer psychology and marketing. There are some evident links between a website design and its brand, yet, with the exception of studies of trust [8] and the emerging field of captology [9], brand has attracted little attention from the HCI community. In marketing research, the website is considered a powerful medium in forming and sustaining a positive attitude towards a brand and its products [10]. Empirical research has demonstrated that attitude toward a web site is a good predictor of consumer brand choice [11]. In this paper, we deal with the opposite research question, namely Is attitude towards brand a good predictor of the user-experience with a website?

T. Gross et al. (Eds.): INTERACT 2009, Part II, LNCS 5727, pp. 638-651, 2009.

(C) IFIP International Federation for Information Processing 2009 


\section{Related Work}

Research on the UX evolved from classical studies of usability as technology moved out of the working context to pervade people's everyday life. The discourse initiated in the late ' 90 s as researchers started considering how factors beyond usability might be integrated in design and evaluation. These considerations were rooted in the recognition of the importance of hedonic qualities [2], such as pleasure [12], fun [5], aesthetics [6], and emotion [4] in HCI.

\subsection{UX Research}

UX research shares some principles which differentiate it from traditional usability studies [1]. Usability research equated quality with absence of problems. UX instead focuses on positive outcomes of interaction and actively tries to add extra value to HCI by designing for emotion, fun and personal fulfilment. Hence, compared to usability, UX research takes a more holistic approach to the definition of quality. This definition subsumes a multi-dimensional model including both pragmatic qualities (traditional usability desiderata) and non-task related aspects, or hedonic qualities, such as beauty, challenge, stimulation and self-expression [2].

Another unique theme of UX is its emphasis on the subjective nature of experience. Traditional usability research emphasized the objectivity of evaluation methods and measures by favouring, for example, user observation over user opinion. Performance variables, such as error rate and time to complete a task, were deemed to be relatively stable among a sample of users with comparable level of computing knowledge, motor and cognitive skills. On the contrary, UX explicitly recognises variations across judgments and focuses on understanding the factors which modulate people's opinions. This theoretical and methodological difference is due to the different research object of the two frameworks. Usability focuses on pragmatic attributes which are "inextricably tied to internally generated or externally given behavioural goals and resulting tasks" [2]. Hedonic attributes, on the other hand, relate to the user's inner self which is, by definition, unique.

Experiences are contextually situated and unfold over time $[4,7,13,14]$. They are the results of the encounters between an active user (with their own unique attitudes, expectations and feelings) and a system (with a set of technical and design characteristics). Individual sources of variations are particularly influent at initial encounter with a system. At this stage, the affect system judges the interface at a visceral level by assigning positive or negative valence to it [4]. As the interaction progress, cognitive elaborations are performed assigning meanings to interface characteristics through interpretation and rationalisation. The affect and the cognitive system are interrelated, so that some affective states are driven by cognition, while cognition can be influenced by affect. Emotions affect cognitive processing by inducing confirmation bias. Positive emotions could cause "mental processes to be more creative more tolerant of minor difficulties" [4] thus potentially favouring evaluation of a system. Negative emotions, generated by a bad first impression, may lead to negative judgement even in the presence of disconfirmatory evidence. 


\subsection{Brand}

A brand is a name, word or symbol which identify the goods or services a vendor and differentiate them from those of the competitors [15]. The value ascribed to brands by consumers is referred to as consumer-based brand equity, i.e., the added value of a product in comparison to an otherwise identical product without the brand's name $[15,16]$. This value lies in the minds of the consumers. It is fuelled by what consumers have experienced, learned, and felt about the brand over time, rather than by objective facts about the brand. Hence, consumer brand equity is subjective and related to the personality, history and preferences of individual customers.

Strong brand equity contributes towards the key components in achieving competitive advantage both in real-life [15, 16] and on-line [17]. In the digital economy, a considerable research effort has been devoted to understanding how brand equity in the real market extends to the digital word [10]. Key features investigated in this line of research are trust and the importance of website design in forming and sustaining a positive attitude towards a brand and its products. Results suggest that branding can facilitate consumers' acceptance of electronic commerce.

\section{Method}

The study investigated the role of brand on the evaluation of the UK-portal for Nike and Reebok. Following the contextual conceptualization of UX, we hypothesized that brand attitude will affect quality judgment of website properties. In particular, we expected that people holding positive attitudes towards the brand of the website would be more positive in their evaluation of the website design. The effect should be stronger with respect to hedonic attributes, which are more susceptible to individual preferences, than to pragmatic attributes which should be more objective.

\subsection{Participants}

A total of 184 second-year students at the University of Manchester participated in this study as part of their course-work for an advanced HCI course. All students had successfully passed an introductory HCI course in their first year. The sample was mainly composed of males (86\%) between the age of 19 and 25 (mean 20.5); 105 students evaluated the Nike website, 79 the Reebok website.

\subsection{Procedure}

Prior to the evaluation, a pre-test questionnaire elicited demographic data and a measure of attitude towards the brand of the website the participants had to evaluate (Nike or Reebok). Participants were then given written instructions on the evaluation procedure and an experimental booklet they had to fill in reporting usability problems, as well as their opinions and impressions on the website. Students were given 4 weeks to perform the evaluation. They were instructed to familiarise themselves with the website, visiting as many sections as possible. To control for a minimum range of common browsing across all participants, they were given a set of information retrieval tasks and had to report their answers in the evaluation booklet. Tasks were designed 
to cover a cross-section of each website sharing some similar features. They included the online shop, the women's section, and the most interactive section of each website. The live websites were evaluated in May 2006. They did not change significantly within the evaluation period.

\subsection{Design}

The study adopted a between-subjects design contrasting brand attitude (3) and website (2). Brand attitude was measured by a pre-test questionnaire. Participants were clustered in three categories: negative, neutral and positive attitude. Participants were also randomly assigned to evaluate either the Nike or the Reebok website.

\subsection{Instruments}

Brand attitude was measured by 3 items ("XX is good value for money"; "XX is a well respected brand"; "People like me wear XX"). Reponses were modulated on a Likert scale, from $1=$ strongly disagree to $5=$ strongly agree. The Perceived Visual Aesthetic scale, PVA was used to provide a measure of classical and expressive aesthetics [6]. Classical aesthetics refers to traditional aesthetic notions emphasising orderly and clear design. It includes items such as "pleasant", "clear", "clean", "symmetrical" and "aesthetic design". Expressive aesthetics is characterised by qualities that capture the user's perception of creativity and originality of the site's design. Relevant items in this dimension are "creative", "fascinating", "original", "sophisticated design", and "use of special effects". The scale also includes a dimension of perceived usability and service quality.

In addition, participants filled in the Interface Quality Scale IQS, a 13 item Likertscale developed by the authors to obtain a measure of usability, content and pleasure in interaction. The statements addressing usability were based on the ISO definition. The statements addressing content quality were based on the elaboration of selected items from the Bernier Instructional Design Scale scale [18]. The statements addressing pleasure were developed by the authors and pilot tested in previous research. The wording of the items is reported in Table 1. Both the PVA and IQS scale were modulated on 7 points $(1=$ strongly disagree; $7=$ strongly agree $)$.

Overall preferences were assessed directly by a 7-point semantic differential item asking users to rank the goodness of the website (good-bad) and 4 Likert-scale items inquiring about future behavioural intentions. Participants were asked to indicate whether "in the next future" they intended to $(a)$ "buy from the website"; $(b)$ "recommend the website to my friend"; $(c)$ "revisit the website" and; $(d)$ "use the website as inspiration for my own design".

\subsection{Websites}

The Nike and the Reebok websites were professionally designed and localised for the UK market. They were composed of a variety of sub-sections that showcased product lines of the two companies and included e-commerce features. The Reebok website was designed in a more traditional style with some animated and interactive elements only in selected sections. The Nike website, on the other hand, featured several animations and some level of interactivity across the entire website. 
(a)

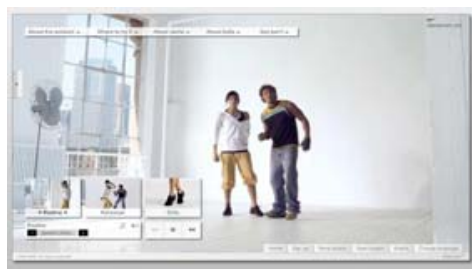

(b)

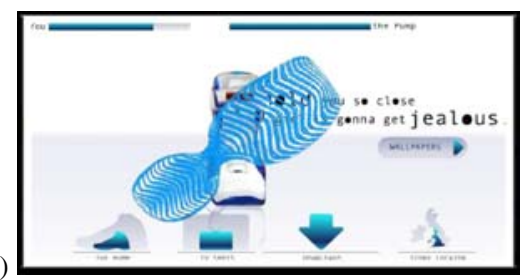

Fig. 1. The Nike's Women's section (a) and the Reebok's Pump shoe section (b)

The Homepage of the Nike website displayed the main website sections. Tasks concentrated on the "Nike Id - Customise and Buy", "Football", and "Women's" sections. The Nike Id section was an online store which allowed the user to design their own piece of footwear or clothing (e.g., changing the colour of shoes or adding initials on shirts) and to buy the item. A range of standard, non-customised items was also available but it was featured less prominently. The Women's section showed a performer doing dance moves as part of a workout routine (Figure 1a). The user could view different clips and browse information on the merchandise featured in the workout. The Football section featured user-generated videos of amateur and semiprofessional players doing football tricks. Users were invited to browse and view the videos, vote for their favourite actor in a league-system, or upload their own videos, although generating content was not mandatory.

The UK portal of the Reebok website consisted of various sections that featured distinct product-lines. Tasks required visiting the online store, "Jamelia's" women's fashion section, and the "Pump shoe" section. The online store featured a traditional HTML design. Jamelia's section displayed videos of the musician and information on where to buy the merchandise featured in them. The pump shoe section was highly interactive (Figure 1b) and included a game where the user was to fight the shoe by moving the mouse and clicking to invoke fight moves. Users could also watch videos, download web art, or locate a store.

\section{Results}

The reliability analysis on the three pre-test items measuring brand attitudes returned a Cronbach's alpha of .68. This value was considered satisfactory for such a short scale as all corrected item-total correlations were above .48. The brand-attitude index was thus computed averaging individual scores on the three items. The index was normally distributed, ranging from 1.33 to 5 (mean $=2.75$, std dev $=.79$ ). Participants were divided into 3 equal-size groups: positive attitude (highest thirdile of the distribution), neutral (middle thirdile), and negative (lowest thirdile). This ordinal index was used as between-subjects factor in the Anovas. The original interval index was used as predictor in the regression analysis.

A behavioural intention index was computed averaging scores on the 4 items enquiring about future behaviour (Cronbach's alpha $=.85)$. Mean scores for all dimensions elicited by the PVA (classical and expressive aesthetics, usability, and service 
Table 1. Factor loadings for the IQS scale

\begin{tabular}{lccc}
\hline & \multicolumn{3}{c}{ Factor } \\
& Content & Usability & Pleasure \\
\hline \hline The level of detail of the content is good & $\mathbf{. 8 1 6}$ & -.171 & .140 \\
The right amount of content is provided & $\mathbf{. 7 0 9}$ & .076 & -.023 \\
The content is relevant & $\mathbf{. 5 5 9}$ & .099 & -.103 \\
The content is of good quality & $\mathbf{. 5 0 2}$ & .119 & .124 \\
\hline The website is easy to use & .023 & $\mathbf{. 9 1 2}$ & -.079 \\
I feel in control when I am using this & -.027 & $\mathbf{. 8 0 7}$ & .033 \\
website & -.030 & $\mathbf{. 7 6 3}$ & .058 \\
The website requires little effort to use & .221 & $\mathbf{. 6 3 8}$ & .091 \\
Using the website is effective & -.165 & .038 & $\mathbf{. 9 2 3}$ \\
\hline I feel pleasure interacting with the website & .070 & -.055 & $\mathbf{. 7 3 7}$ \\
The website is pleasurable to look at & .145 & -.020 & $\mathbf{. 6 9 2}$ \\
The website has design features I like & .020 & .097 & $\mathbf{. 6 4 1}$ \\
The website evokes positive feelings & .208 & .159 & .193 \\
\hline The website is trustworthy &
\end{tabular}

quality) were also computed (Cronbach's alpha $>.80$ ). Scores on the IQS items were entered into an exploratory factor analysis for each site separately and using the combined data set. The factors were extracted applying the Maximum Likelihood method with Oblimin rotation, as it is acknowledged that different dimensions of the user experience tend to correlate $[3,6,13]$. The three analyses reported consistent factorial configurations. Loading of variables on factors for the entire sample are reported in Table 1. To simplify interpretation, variables are ordered and grouped by size of loading and loadings above .50 are reported in bold. Inspection of the scree-test plot and comparison of the goodness of fit of different configurations allowed the identification of three main factors which could clearly be interpreted as usability, content and pleasure. They accounted for $65 \%$ of the variance (goodness of fit: $\chi_{(42)}^{2}=75.7, p<.01$ ).

To summarise, 7 variables were tested in the study: classical and expressive aesthetics, usability and service quality (collected by the PVA scale), and usability, pleasure and content (collected by the IQS). Correlations between mean scores on each dimension are reported in the lower part of Table 2. With the exception of the relationship between expressive aesthetics and the two usability indexes, all other variables significantly correlated with each other. To account for these correlations, factor scores were computed for each dimension using the Anderson-Rubin approach [19]. Factor scores are weighted combination of scores on a series of factors which provide an estimate of the scores participants would have received on each factor if they would have been measured directly. The Anderson-Rubin approach produces scores which are uncorrelated with each other even if the original scores are correlated. By taking away the shared part of variance between factors, factor scores provided less biased measures of the $7 \mathrm{UX}$ dimensions. The correlations between factor 
Table 2. Correlation between mean scores (lower part) and factore scores (upper part) on UX dimensions $(*=\mathrm{p}<.05 ; * *=\mathrm{p}<.01)$

\begin{tabular}{|c|c|c|c|c|c|c|c|}
\hline & 1 & 2 & 3 & 4 & 5 & 6 & 7 \\
\hline $\begin{array}{l}\text { 1. } \begin{array}{l}\text { Content } \\
\text { IQS }\end{array}\end{array}$ & & .000 & .000 & .085 & $\begin{array}{l}.274 \\
(* *)\end{array}$ & $\begin{array}{l}.279 \\
(* *)\end{array}$ & .078 \\
\hline $\begin{array}{l}\text { 2. Usability } \\
\text { IQS }\end{array}$ & $\begin{array}{l}.494 \\
(* *)\end{array}$ & & .000 & $\begin{array}{l}.191 \\
(*)\end{array}$ & $\begin{array}{l}.184 \\
(* *)\end{array}$ & $\begin{array}{l}.720 \\
(* *)\end{array}$ & $\begin{array}{l}.636 \\
(* *)\end{array}$ \\
\hline $\begin{array}{ll}\text { 3. } & \text { Pleasure } \\
\text { IQS }\end{array}$ & $\begin{array}{l}.421 \\
(* *)\end{array}$ & $\begin{array}{l}.365 \\
(* *)\end{array}$ & & $\begin{array}{l}.299 \\
(* *)\end{array}$ & $\begin{array}{l}.611 \\
(* *)\end{array}$ & .103 & .075 \\
\hline $\begin{array}{l}\text { 4. Classical } \\
\text { Aesthetics } \\
\text { PVA }\end{array}$ & $\begin{array}{l}.427 \\
(* *)\end{array}$ & $\begin{array}{l}.483 \\
(* *)\end{array}$ & $\begin{array}{l}.614 \\
(* *)\end{array}$ & & .000 & .000 & .000 \\
\hline $\begin{array}{l}\text { 5. Expressive } \\
\text { Aesthetics } \\
\text { PVA }\end{array}$ & $\begin{array}{l}.302 \\
(* *)\end{array}$ & .050 & $\begin{array}{l}.618 \\
(* *)\end{array}$ & $\begin{array}{l}.393 \\
(* *)\end{array}$ & & .000 & .000 \\
\hline $\begin{array}{l}\text { 6. Usability } \\
\text { PVA }\end{array}$ & $\begin{array}{l}.520 \\
(* *)\end{array}$ & $\begin{array}{l}.798 \\
(* *)\end{array}$ & $\begin{array}{l}.372 \\
(* *)\end{array}$ & $\begin{array}{l}.604 \\
(* *)\end{array}$ & .066 & & .000 \\
\hline $\begin{array}{l}\text { 7. Service } \\
\text { Quality } \\
\text { PVA } \\
\end{array}$ & $\begin{array}{l}.499 \\
(* *)\end{array}$ & $\begin{array}{l}.636 \\
(* *)\end{array}$ & $\begin{array}{l}.334 \\
(* *)\end{array}$ & $\begin{array}{l}.427 \\
(* *)\end{array}$ & $\begin{array}{l}.251 \\
(* *)\end{array}$ & $\begin{array}{l}.651 \\
(* *)\end{array}$ & \\
\hline
\end{tabular}

scores are reported in the upper part of Table 2. The significant correlations between similar dimensions measured by different scales provide support to validity of the measures.

Each mean and factor scores were entered as dependent variables into a univariate Anova with Website (2) and Brand-Attitude (3) as between-subjects factors. When the two analyses returned similar results, only those obtained on factor scores are reported as they are more conservative. Otherwise, the difference is acknowledged. For ease of interpretation, however, all descriptive statistics are computed on mean scores. Partial eta squared statistics (partial $\eta^{2}$ ) were used as estimate of effect sizes. Partial $\eta^{2}$ are computed considering the variance attributable to the effect of interest plus error [19]. As a general guideline, $\eta^{2}=.01$ are considered small, $\eta^{2}=.06$ medium, $\eta^{2}=.14$ large [20]. Post Hoc tests for the three levels of the brand attitude factor were computed using the Least Significance Difference algorithm.

\subsection{Usability}

Significant results returned from the two Anovas using usability factor scores as dependent variables are summarized in Table 3. Both analyses showed significant, medium-sized effects for website. On average, the Reebok website was evaluated as more usable than the Nike one. The effect of brand attitudes was also significant in both analyses, although the effect size obtained on the PVA scale was stronger than that obtained on the IQS scale.

Post-hoc analyses revealed that the effect of brand attitude was mainly due to participants who held negative attitudes towards the brand, as they were more critical in the evaluation (Figure 2). No significant differences emerged between people with neutral and positive attitudes, although the linear trend was still evident. 
Table 3. Anovas results for usability factor scores

\begin{tabular}{llrrrr}
\hline \hline Dependent variable & & & & & \\
& \multicolumn{1}{c}{ Source } & $\mathrm{df}$ & \multicolumn{1}{c}{$\mathrm{F}$} & \multicolumn{1}{c}{ Sig. } & $\eta_{\mathrm{p}}{ }^{2}$ \\
\hline \multirow{2}{*}{ Usability PVA } & Brand Attitude & 2,142 & 7.39 & .001 & .09 \\
& Website & 1,142 & 13.52 & .001 & .09. \\
\cline { 2 - 6 } & Brand Attitude & 2,172 & 2.72 & .07 & .03 \\
\multirow{2}{*}{ Usability IQS } & Website & 1,172 & 14.24 & .001 & .07 \\
\hline
\end{tabular}

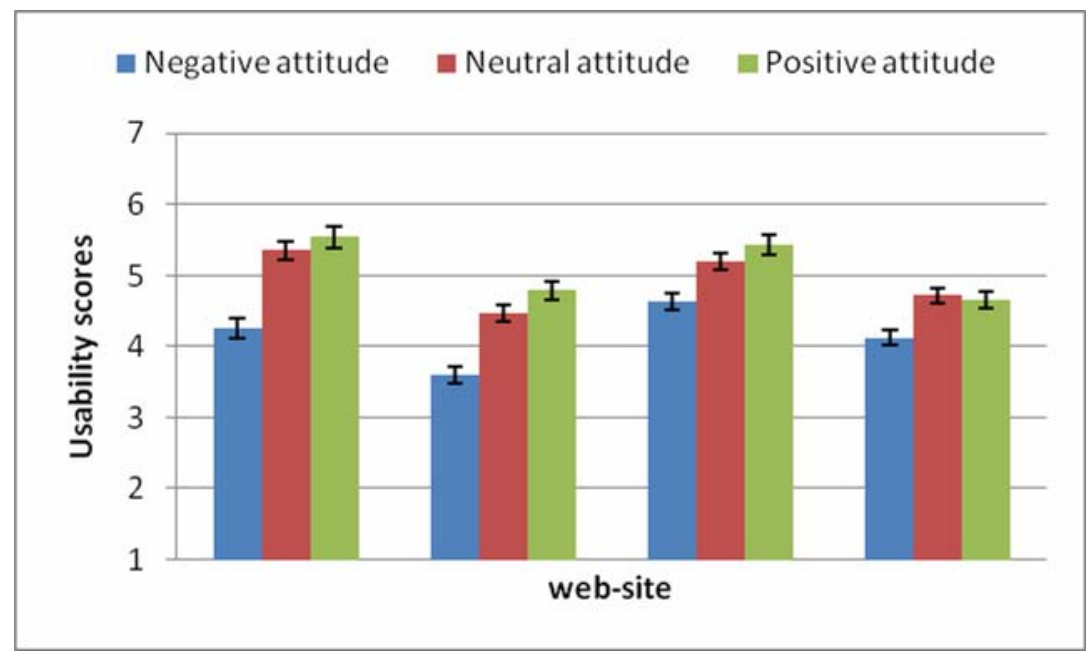

Fig. 2. Mean and standard error scores on usability as a function of experimental conditions

\subsection{Aesthetics}

The Anova using factor scores on classical aesthetics as dependent variable returned only a significant, medium-sized effect for brand predisposition $\left(F_{(2,142)}=4.57, p<\right.$ .05 , partial $\left.\eta^{2}=.06\right)$. A linear trend was evident. Participants holding a negative attitude towards the brand evaluated the web site as less attractive (mean $=4.50$; std error $=.12$ ), than participants holding a neutral attitude (mean $=4.98$; std error $=.12)$, or participants holding a positive attitude $($ mean $=5.31$; std error $=.14)$. Post-hoc tests showed significant differences between participants holding negative attitudes and the other two groups.

The Anova with factor scores on expressive aesthetics as the dependent variable indicated a significant effect for web-site $\left(F_{(12,142)}=31.7, p<.001\right.$, partial $\left.\eta^{2}=.18\right)$ and a significant interaction web-site $*$ attitude $\left(F_{(2,142)}=4.12, p<.05\right.$, partial $\left.\eta^{2}=.06\right)$. Nike was clearly preferred over Reebok on this aesthetic dimension. Participants holding better attitudes towards Nike were also more positive in the evaluation of expressive aesthetics; whereas the evaluation of Reebok was unaffected by participants' attitudes towards the brand. 


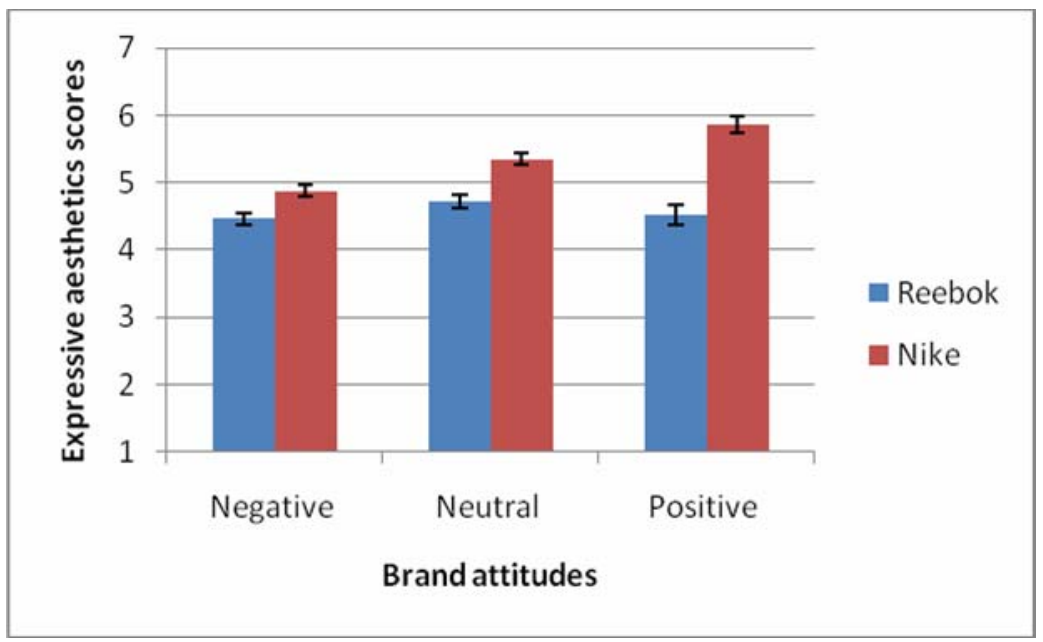

Fig. 3. Mean and standard error scores on expressive aesthetics as a function of experimental conditions

\subsection{Pleasure}

A significant main effect for website $\left(F_{(2,172)}=19.27, p<.001\right.$, partial $\left.\eta^{2}=.12\right)$ and for brand affinity $\left(F_{(2,172)}=6.87, p<.01\right.$, partial $\left.\eta^{2}=.07\right)$ were returned by the Anova on pleasure factor scores. Overall, participants tended to prefer the Nike website (mean difference $=0.55$ ) and their evaluation was modulated according to their attitudes towards the brand: the most positive the attitude, the most positive the evaluation. In particular, post-hoc tests revealed that people holding negative attitudes were significantly different in their evaluation from people holding neutral or positive evaluations. No significant difference emerged between the two latter groups.

\subsection{Content}

The Anova using factor scores on content as dependent variable returned a marginally significant effect for brand attitude $\left(F_{(2,172)}=2.61, p=.07\right.$, partial $\left.\eta^{2}=.03\right)$. The mean trend is consistent with previous analyses showing a linear improvement in the evaluation as a function of attitudes. However, post-hoc test indicated that the effect is significant only for the comparison between negative and positive attitudes.

The effect of brand attitude cleanly appeared when the mean scores were analysed $\left(F_{(2,172)}=7.11, p<.01\right.$, partial $\left.\eta^{2}=.08\right)$. All differences between consecutive levels of attitudes were significant. The difference in the two analyses was probably due to the strong correlation between content and usability (Table 2).

\subsection{Service Quality}

No significant results were returned from the factor scores on service quality. On the contrary, the Anova on mean scores indicated a large significant effect for brand attitude $\left(F_{(2,156)}=10.99, p<.001\right.$, partial $\left.\eta^{2}=.12\right)$ and a small effect for website 
$\left(F_{(2,172)}=4.89, p<.05\right.$, partial $\left.\eta^{2}=.03\right)$. These effects indicated that people holding negative attitudes were more critical in evaluating the quality of the website than people with a neutral or a positive attitude. On average, the service quality of Reebok was scored slightly better that that of Nike (mean difference $=.33$ )

\subsection{Overall Evaluation}

The overall evaluation of website goodness was affected by brand attitudes $\left(F_{(2,178)}=\right.$ $6.89, p<.001$, partial $\left.\eta^{2}=.08\right)$. People holding negative attitudes towards the brand evaluated the website more negatively than people holding neutral or positive attitudes.

\subsection{Behavioural Intentions}

A stepwise regression analysis was run to investigate the relative influence of different UX dimensions in predicting participants' behavioural intentions with the website. Using this technique, significant variables are entered in the regression model according to their relative contribution to it. The entire sample was used for the analysis. Factor scores on classical and expressive aesthetics, usability (measured by the PVA scale), content and brand attitudes (interval scale index) were entered as predictors. Four significant models were returned, $p<.001$ (Table 4). Brand attitude (BA), expressive aesthetics (EA), usability (U) and classical aesthetics (CA) together accounted for $46 \%$ of the variance in behavioural intention with the website (model 4).

Brand attitude was the most important predictor of behavioural intentions, accounting for $22 \%$ of its variance. The second variable entered in the model was expressive aesthetics which added another $13 \%$ of variance. Usability accounted for $7 \%$ and classical aesthetics for $5 \%$ of the variance.

Table 4. Significant models returned from the stepwise regression analysis on behavioural intentions

\begin{tabular}{lcrrr}
\hline \hline & & & & \\
Model & $\mathrm{R}$ & $\mathrm{R}$ Square & Adjusted R Square & Std. Error of the Estimate \\
\hline 1. (Constant), BA & .473 & .224 & .218 & 1.48946 \\
2. (Constant), BA, EA & .589 & .347 & .338 & 1.37073 \\
3. (Constant), BA, EA, U & .646 & .417 & .405 & 1.29918 \\
4. (Constant), BA, EA, U, CA & .686 & .471 & .456 & 1.24270 \\
\hline \hline
\end{tabular}

\section{Conclusion}

The objective of this study was to assess the effect of brand attitudes on the evaluation of websites. For this purpose we have tested a large sample of evaluators asking them to rate the quality of two corporate websites (Nike and Reeebok) with an array of UX 
Table 5. Summary of significant effects from the Anovas on factor scores

\begin{tabular}{lllr}
\hline \hline UX dimension & \multicolumn{1}{c}{ Brand Attitudes } & Website & Interaction \\
\hline ability & Negative $<$ Neutral = Positive & $\mathrm{R}>\mathrm{N}$ & n.s. \\
Classical Aesthetics & Negative $<$ Neutral = Positive & $\mathrm{R}=\mathrm{N}$. & n.s. \\
Expressive Aesthetics & $\begin{array}{l}\text { Negative }<\text { Neutral = Positive } \\
\text { only for Nike }\end{array}$ & $\mathrm{R}<\mathrm{N}$ & Yes \\
Pleasure & Negative $<$ Neutral = Positive & $\mathrm{R}=\mathrm{N}$. & n.s. \\
Content & Negative $<$ Positive & $\mathrm{R}=\mathrm{N}$ & n.s. \\
Service quality & n.s. & $\mathrm{R}=\mathrm{N}$ & n.s. \\
Overall goodness & Negative $<$ Neutral = Positive & $\mathrm{R}=\mathrm{N}$ & n.s. \\
\hline \hline
\end{tabular}

questionnaires. Results suggested that the evaluation was influenced by participants' previous knowledge and expectations of the website brand. A summary of significant effects returned from the analyses of variance conducted on the factor scores on each individual UX dimension is reported in Table 5.

Attitude towards the brand proved to be an important moderator of judgments, affecting not only the perception of hedonic qualities (classical aesthetics, expressive aesthetics and pleasure) but also the perception of some pragmatic qualities (usability and in part content), which are generally considered to be more objective. A linear trend appeared in all dimensions: evaluation improved alongside attitudes. The posthoc analyses suggested however that, with the exception of content, the difference in all dimensions was due to participants holding negative attitudes who were more critical in their evaluation than both participants holding neutral or positive attitudes. This is consistent with the 'negativity bias' widely documented in psychological research implying that people's reaction to negative stimuli evoke stronger and more rapid physiological, cognitive, emotional, and social responses than neutral or positive stimuli [21].

With the only exception of expressive aesthetics, which was affected by the interaction between brand attitudes and website, the effect of brand was reliable across the websites. Overall, Nike was evaluated better on the expressive aesthetics dimension, whereas Reebok was favoured on usability and content. No significant differences emerged in the overall evaluation of the website goodness. The trade-off between expressive aesthetics and usability was shown in more controlled experimental settings suggesting that engaging design tend to add a level of complexity to the detriment of ease of use $[3,7]$.

\subsection{Brand and UX}

The effect of brand on the user evaluation of web-sites supports the prevailing conceptualization of UX stating that experiences are intrinsically subjective and dependent on the evaluator personality, expectations, and goals $[2,7,14,15]$. No conclusive evidence can be derived from this study to understand how exactly brand affects the evaluation of websites. Theoretically, this effect may be elicited at different 
processing levels [4]. At the initial encounter with the website, brand may influence the output of the affect system, acting as a mental determinant which induces a visceral reaction to it. This reaction can subsequently bias the output of the cognitive system with a general halo effect. The importance of first impressions on the evaluation of websites has been demonstrated in previous UX studies. Participants reliably decided which design they liked and which ones they did not like within 500ms exposure [22] and these impressions were not transient [23]. Furthermore a large corpus of psychological research has provided evidence that even subliminal exposure to a brand may affect consumer mood and choice [24].

However, brand can also influence cognitive processing directly as an attitudinal variable. In this case brand can be used as a criterion signalling trust, identification and reliability. We believe that the specific nature of our sample target (university students with a background in HCI and previous experience in evaluation) should make them less prone to evaluation bias, and may suggest a direct effect of brand on cognitive elaboration of judgements.

\subsection{Limitations and Future Research}

The study reported in this paper has several limitations which may have affected its reliability. An obvious limitation regards the nature of the sample. More research is needed to understand how these findings extend to different user categories, including usability professionals and final users. Similarly, the study should be replied using a larger set of web-sites as stimuli and more robust measures of attitudes towards brand. Despite of these limitations, the large sample tested in the study and the strong reliability of the effect which persists across different measures and operational definitions of UX dimensions, is an encouraging indication of external validity.

The choice of favouring an ecological setting over a laboratory-based experiment implied that results may be affected by confounding factors. For example, we had no information about the browsing behaviour of the evaluators, or about the environmental setting where the evaluation was carried out. Furthermore, as the evaluation addressed two live websites we did not have direct control on their content. These problems were, at least partially, counteracted by taking into consideration a number of explicit and implicit information provided by the evaluators in their reports. We checked the quality of the reports and discarded those students who appeared not to have put enough effort into the assignment. Furthermore, participants were motivated in performing the evaluation to the best of their capabilities, as the assignment accounted for $20 \%$ of their mark at the module.

The study presented in this paper has important implications for UX practice and research. On a practical point of view, it warns evaluators and designers of the possibility of a systematic bias in the evaluation affecting not only hedonic qualities but also usability. On a research perspective, this study calls for a re-examination of current UX models assuming that experiences are composed of distinct and orthogonal attributes. Tractinsky \& Zmiri [25], for instance, highlighted three attributes: usability, aesthetics, and symbolism which were considered to be independent of each other. In their model, aesthetics is regarded as the sensorial experience generated by the look and feel of the interface. Symbolism refers to meanings and associations which are elicited during cognitive elaborations. Our study provides support to the importance 
of symbolism in UX but it questions its conceptual independence. Both UX research and practice must seriously consider the operational definition of quality dimensions, as we have demonstrated that mean scores, traditionally used as indications of user evaluations, are prone to over-estimation of statistical effects.

\section{Acknowledgement}

We are grateful to Mark Hassenzahl for his suggestions on the statistical analyses reported in this paper and the many stimulating discussions on validity in HCI research.

\section{References}

1. Hassenzahl, M., Tractinsky, N.: User experience - A research agenda. Behaviour \& Information Technology 25, 91-97 (2006)

2. Hassenzahl, M.: The Interplay of Beauty, Goodness, and Usability in Interactive Products. Human-Computer Interaction 19, 319-349 (2004)

3. De Angeli, A., Sutcliffe, A., Hartmann, J.: Interaction, usability and aesthetics: what influences users' preferences? In: 6th conference on Designing Interactive systems DIS2006, pp. 271-280. ACM, State College (2006)

4. Norman, D.A.: Emotional Design: Why We Love (or Hate) Everyday Things. Basic Books, New York (2004)

5. Blythe, M.A., Overbeeke, K., Monk, A.F., Wright, P.C. (eds.): Funology: From Usability to Enjoyment. Kluwer Academic Publishers, Dordrecht (2005)

6. Lavie, T., Tractinsky, N.: Assessing dimensions of perceived visual aesthetics of web sites. International Journal of Human-Computer Studies 60, 269-298 (2004)

7. Hartmann, J., Sutcliffe, A., De Angeli, A.: Towards a theory of user judgment of aesthetics and user interface quality, vol. 15, pp. 1-30. ACM Press, New York (2008)

8. Briggs, P., Burford, B., De Angeli, A., Lynch, P.: Trust in online advice. Soc. Sci. Comput. Rev. 20, 321-332 (2002)

9. Fogg, B.J.: Persuasive technology. Morgan Kaufmann Publishers, San Francisco (2003)

10. Chaffey, D., Ellis-Chadwick, F., Johnston, K., Mayer, R.: Internet Marketing - Strategy, Implementation and Practice. Prentice Hall, Essex (2006)

11. Byung-Kwan, L., Ji-Young, H., Wei-Na, L.: How Attitude Toward the Web Site Influences Consumer Brand Choice and Confidence While Shopping Online 9 (2004)

12. Jordan, P.W.: Designing Pleasurable Products: An Introduction to the New Human Factors. Taylor \& Francis Ltd., London (2000)

13. Hartmann, J., Sutcliffe, A., De Angeli, A.: Investigating attractiveness in web user interfaces. In: CHI 2007, pp. 387-396. ACM Press, New York (2007)

14. Hartmann, J., De Angeli, A., Sutcliffe, A.: Framing the User Experience: Information Biases on Website Quality Judgement. In: CHI 2008, pp. 855-864. ACM, Florence (2008)

15. Aaker, D.A.: Building strong brand. Free Press, New York (1996)

16. Keller, K.L.: Conceptualizing, Measuring, Managing Customer-Based Brand Equity. Journal of Marketing 57, 1-22 (1993)

17. Ward, M.R., Lee, M.J.: Internet shopping, consumer search and product branding. Journal of Product \& Brand Management 9, 6 (2000) 
18. Bernier, M.J.: Establishing the psychometric properties of a scale for evaluating quality in printed educational materials. Patient Education and Counseling 29, 283-299 (1996)

19. Tabacknick, B.G., Fidell, L.S.: Using multivariate statistics. Pearson International Edition (2007)

20. Pallant, J.: SPSS Survival Guide. Allen \& Unwin (2007)

21. Taylor, S.E.: Asymmetrical effects of positive and negative events: The mobilizationminimization hypothesis. Psychological Bulletin 110, 67-85 (1991)

22. Lindgaard, G., Fernandes, G., Dudek, C., Browñ, J.: Attention web designers: You have 50 milliseconds to make a good first impression! Behaviour \& Information Technology 25, $115-126$ (2006)

23. Tractinsky, N., Cokhavi, A., Kirschenbaum, M., Sharfi, T.: Evaluating the consistency of immediate aesthetic perceptions of web pages, vol. 64, pp. 1071-1083. Academic Press, Inc., London (2006)

24. Theus, K.T.: Subliminal advertising and the psychology of processing unconscious stimuli: A review of research. Psychology and Marketing 11, 271-290 (1994)

25. Tractinsky, N., Zmiri, D.: Exploring attributes of skins as potential antecedents of emotion in HCI. In: Fishwick, P. (ed.) Aesthetic Computing, pp. 405-422. MIT Press, Cambridge (2005) 